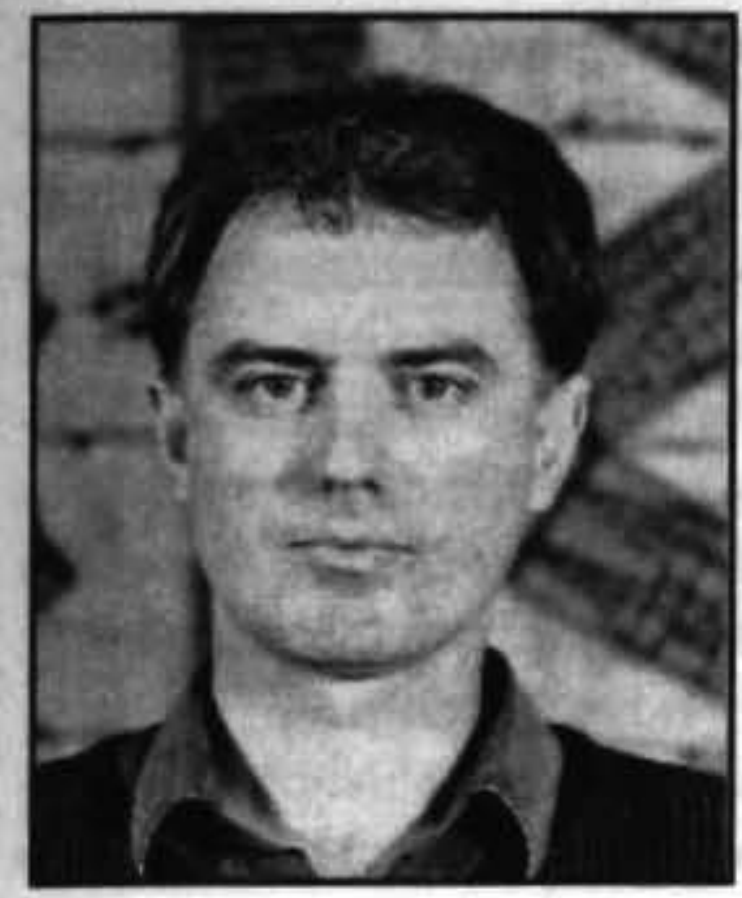

\title{
MICRO-SOCIOLOGY AND THE STUDY OF WORKPLACE ACCIDENTS AND INJURY
}

\author{
Mike Lloyd \\ Sociology \& Social Policy \\ Victoria University of Wellington
}

pirical material from the recent ministerial inquiry into workplace injuries and fatalities at Tranz Rail, this paper considers the inquiry's question of whether 'any culture or cultures within Tranz Rail may be relevant to the operation of a safe and healthy place of work'. Application of discourse analysis suggests that the culture question is indeed important, but not quite in the areas suggested by some of the contributors to the Tranz Rail inquiry. The paper foregrounds 'textually mediated social organisation' as a key feature of contemporary social worlds, including the workplace.

Keywords: Health and Safety, workplace culture

Workplace accidents and injury have been a topic of study for many social science disciplines. Within sociology the predominant approach is a macro-focus on the social distribution and structuring of accidents and injury. A micro-sociological focus is also useful, and to illustrate this an analysis is presented of the recent ministerial inquiry into Tranz Rail occupational safety and health. Part of this inquiry concerned the important question of whether accidents and injuries at Tranz Rail were connected to workplace culture, a question that proved very difficult to answer. The intent here is not to criticise the inquiry's work, instead the analysis shifts from a causal-explanatory focus to one seeking an understanding of process, particularly the importance of what Smith (1990) calls 'textually mediated social organisation'.

\section{Micro-sociology}

Within sociology the term micro refers to a focus on the fine detail of commonplace, everyday life. This includes things like, media stories, conversations, and people interacting in bounded spaces like factories, restaurants, buses, city streets and so on. Traditional macro concerns for ethnic, gender and class inequalities can be useful with these topics, but what characterises the micro point of view is a predominant concern for how the local is organised. How do people build social worlds, together, on a hereand-now basis? There are debates about the cogency of the labels micro and macro, and where various perspectives should be placed, but rather than engage these, micro-sociology is elaborated below by using Cooper and Law's (1995) distinction between distal and proximal sociology.

For most of its history sociology has offered distal views of its subject matter, but roughly since the 1960 s the criti- cism arose that these views assumed too much. Sociologists dealt with results, such as social structures, rather than the processes that lead to those results - the focus of the proximal view. In short, 'the distal is constituted by action at a distance; the proximal, through action by contact' (ibid: 239).

Given that contemporary sociology is full of variations on this distinction, why is this version worth mentioning? First, note that Cooper and Law are applying it to the study of organisations. The topic of this conference - Labour, Employment and Work - is an area saturated with organisations, and the distal/proximal distinction is most useful here. Under the distal view an organisation is a definable system with a strong boundary; it is a structure that can be measured. Hence, there is the study of organisations, plural. In contrast, the proximal view emphasises assemblages of organising. It turns the topic of study from a noun to a verb, to networks and circuits of continuous contact and motion. The distal focus tends to take individuals, subgroups, and their motives and actions as discrete features of an organisation, whereas the proximal focuses on the interpenetration of a multitude of sub-units, that will organise in ways that although structured have a 'first-timethrough' contingent character.

Second, while Cooper and Law favour the proximal view they are not offering a simple either/or choice, where we either have stability associated with powerful structures, or the instability associated with process and uncertainty. The real utility of the distinction is how it draws attention to the nature of the relationship between effect and process: a proximal (micro-) sociology seeks to analyse "forces and agents that order relatively stable effects (such as organisations, societies) out of intrinsically partial and precarious processes" (1995: 240). Or to adapt Latour (1987), 
an organisation does not cause and determine everything that happens within its boundaries, rather the recognition of its boundaries and its very existence depends precisely on what elements are held together.

This second point has an important implication for the common social scientific focus on power and interest. It may seem that the proximal view is circular: if it is admitted that there is stability in organisations, but one wants to focus on organising, why not just admit that ultimately the result is the power and reality of organisations? However, as Cooper and Law nicely put it, they are after virtuous, and not vicious, circularity. Organisations convince us of their material existence: they build up truths about themselves through for example, their hierarchies, logos, mission statements, records, and report sheets. In this, "truth, then, is integrally linked to ... power. And power depends on truth. That is the character of circularity" (1995: 256). By composing themselves of collections of multiple entities, organisations self-validate, they point to what they are made of (they truly exist), which in turn is linked with power as the organisation can then enrol yet more entities and then translate others' actions. By taking seriously the multiplicity of materials (natural and social) that organisations are built from, simplistic views of power as political prejudice or domination disappear. For the world isn't endlessly malleable. It cannot be bent endlessly to an arbitrary political will. This is because successful heterogeneous engineering has to cope with the resistances put up by that world whether these be social or natural. Indeed, it needs to find ways of incorporating both into its ordering arrays (ibid: 256).

It is precisely the incorporation of both the natural and the social into organising that we see so clearly in the ministerial inquiry into Tranz Rail. Below, the tenets of proxi$\mathrm{mal} / \mathrm{micro}$ - sociology are used to analyse this case.

\section{The Tranz Rail inquiry and the 'culture prob- lem'}

On June 28, 2000, the Minister of Labour announced the terms of reference for a ministerial inquiry (hereafter, 'the Inquiry') into the safety practices and standards of Tranz Rail, the private company that had bought the previously government-owned New Zealand Rail. Media statements made it clear that the Inquiry was prompted by the death of a railway shunter in May, the fifth death of a Tranz Rail employee within a year. Whilst these five deaths provided an obvious hook for the media, concern about workplace safety in the rail and port industry had existed for many years, with the Rail and Maritime Transport Union expressing formal concern about high rates of injury and fatality as early as 1995 (Armstrong, 2000).

The rationale for the Inquiry was to establish whether there were any 'systemic factors' that contributed to the accident situation and, if so, whether they arose out of the safety regulatory regime governing Tranz Rail's activities. The Inquiry was based on nine specific terms of reference and heard oral submissions (mostly derived from written submissions) in a five-day period. Given the amount of material the Inquiry generated, I propose to limit analysis to the term of reference to do with 'culture' (hereafter 'the culture problem'), viz: 'Identify and consider any culture or cultures (i.e., influences or attitudes which affect practices and behaviour) within Tranz Rail and its employees and contractors that may be relevant to the operation of a safe and healthy place of work' (Ministerial Inquiry, 2000: 2).

Tranz Rail's submission has a whole section devoted to the culture problem. In that part of their submission it is not surprising to see ambivalence and difficulty, for as Williams has famously put it, "Culture is one of the two or three most complicated words in the English language" (1988: 87). Tranz Rail's submission devotes a whole page to defining culture. It is noted that culture is an intangible, that it is difficult to determine with any specificity, and then "culture is defined as: The formal or informal values, philosophies and norms that interact and overlap to create the fabric we call culture" (Tranz Rail, 2000: 1). After this definition, the submission reiterates the difficulty in pinpointing culture, and also mentions that "the sub-culture of each group will be examined" (ibid: 1).

The key elements of heterogeneous engineering that make organisations seem so stable and structured - the natural, social and discursive - are all operating in the Inquiry, whose task is to work out (and put on paper) what is significant from amongst an array of possibilities. Just what will be admitted as relevant in attempting to explain the high rates of accidents and injuries at Tranz Rail? At times, the 'natural' must be allowed to speak (partly) for itself: it is obvious that when someone is crushed by a train, the immediate cause of death or injury is a soft body coming into contact with a hard machine which has no sympathy for humans. But what was the broader context within which this fatal contact occurred? Here, the social organisation of the workplace becomes the focus, and this in turn can reconfigure the consideration of material objects. There is no clear answer, always debate. For example, some time was given over in the oral submissions to questioning whether the floor of one rail carriage was actually rusted right through, as the union claimed, or whether this was spurious, as Tranz Rail claimed. Or, when a power pole rots below the ground, that is a natural occurrence, but when it falls and crushes a worker, we ask why precautions were not taken. Thus, the culture problem makes the social its focus, but not to the isolation of the natural, to which it is inextricably linked. That is, accidents and injuries may be found to have a 'natural' component but once established this opens up the question of what other social factors were involved, and oftentimes it may be unclear just what mix of the natural and social is involved. The constant debate and contingency are good reason to follow Callon (1998) and call the Inquiry a hybrid forum, that is, a constantly debated mix of the natural, social and discursive.

In this hybrid forum we see the utility of virtuous circular- 
ity. To make a decision on the culture problem (to find the truth) we need first to locate what culture actually is. But no single actor in the hybrid forum has the ability to signify the truth, and this is why so much effort is given over to producing convincing (and lengthy) submissions. In this, textual organisation itself becomes crucial for it shapes and produces understandings. As O'Neill has put it, 'the story of anything is itself another story of the choices made to tell it in the way we have it here' (2000: 101). Such a concern with interaction between form and content is very useful in considering the culture problem, and below this is developed by analysing the 'Historical Perspective' extract (from three pages into the Tranz Rail submission).

\section{Historical Perspective}

1880s - 1981: For almost a century, New Zealand's railway system was owned by the Government and, in fact, was a Government Department with is own Minister for Railways. Features of this period included an entrenched bureaucratic culture. The Department conducted its business with a focus on engineering and, as an adjunct to the business, pursued social and political objectives.

The Department operated in a protected environment in that goods or freight were not able to be transported by road for any distances greater than 30 miles, then 40 miles and later 150 kilometres. The culture during this period was based on the ideal of "a job for life". Given the security of tenure for most employees, the Department was able to foster its own sense of family and community. For example, many employees lived in Railway houses, owned by the Department, at minimal rents. As these houses were usually grouped together, working for the Department was not only a job but a lifestyle.

The Department was a hierarchical, military-type structure. Promotional opportunities were based primarily on length of service as opposed to performance.

1982 - 1990: During this period, the Department became a Government Corporation known as NZ Railways Corporation. The Government at the time embarked on the commercialisation of the old railways Department. Protection from road transport competition was lifted. There was a shift in focus and fundamental raison d' etre of the organisation from engineering and social goals to cost efficiency and with emphasis on downsizing the organisation.

During this time, the hierarchical structure of the organisation was dismantled to a large degree in that a number of layers of management were eliminated and the focus for front line employees was the improvement of productivity.

Over this period staff numbers reduced from more than 20,000 to approximately 6,800 by 1990 .

1990 - 1993: In 1990, the Corporation became a
Government-owned company, NZ Rail Limited. The focus of the organisation moved to achieving operating profit, not merely cost reduction. The deregulation of the road transport industry resulted in intense competition for freight movement. To be successful in the new environment, NZ Rail Limited concentrated on meeting customer needs and cost containment.

The restructuring and rationalisation of the company continued but not at the same rate as the previous era. In terms of staff numbers, reduction during this period was from 6,800 employees to approximately 5,000 by 1993 .

By the end of this period, NZ Rail Limited was a profitable organisation.

1993-present: NZ Rail was sold to a consortium of private owners including Wisconsin Central Transportation Limited, Berkshire Partners and Fay Richwhite.

\section{Proximal/Micro Analysis}

This extract contains facts, figures, and words that refer to previous events. We could check the dates and figures it contains, and in doing so we could make a judgement about whether the parameters of this story are accurate and valid. But in making a proximal analysis we need to go beyond a reference, or correspondence, model of language. In short, we need to consider the pragmatics of this extract: what it does, where it takes us, the effect of the story it tells. This approach has been extant for some time in the study of organisations, for example, in 1957 Selznick commented:

\begin{abstract}
To create an institution we rely on many techniques for infusing day-to-day behaviour with long-run meaning and purpose. One of the most important of these techniques is the elaboration of socially integrating myths. These are efforts to state, in the language of uplift and idealism, what is distinctive about the aims and methods of the enterprise. The assignment of a high value to certain activities will itself help to create a myth, especially if buttressed by occasional explicit statements (quoted in Parker, 2000: 134).
\end{abstract}

While the Historical Perspective extract occurs admidst an attempt to answer the culture problem it is also a socially integrating myth. It functions as a foundation story, that is, it is one legitimated tale of the foundation of Tranz Rail and like any tale, it is deeply moral, has a particular form, and attempts to convince readers of a particular view.

The tale has a simple narrative form: A long time ago there was a group of people who had a bad way of living, but then after a period of trials some new people triumphed and things were made good. It is a classic story of change and contest between good guys/good ways of doing things and bad guys/bad ways of doing things. It is easily interpretable, but as a brief elaboration we can pick out a 
few key pieces from the extract, and put story equivalents in brackets. The Historical Perspective story begins, "For almost a century" (A long time ago), "New Zealand's railway system was owned by the Government" ... "Features of this period included an entrenched bureaucratic culture" where "working for the Department was not only a job but a lifestyle" and "Promotional opportunities were based primarily on length of service as opposed to performance" (the people lived in a state of darkness/there was a scourge upon the land). (But then something new happened) '1982-1990: ... the commercialisation of the old Railways Department' emphasising 'cost efficiency'. (The people found this new way a little frightening) "layers of management were eliminated and the focus of front line employees was the improvement of productivity"; "Over this period staff numbers reduced from more than 20,000 to approximately 6,800 by 1990 ". (But when all was over, the people lived happily ever after) "By the end of this period, NZ Rail Limited was a profitable organisation" (because along came the knight in shining armour) "NZ Rail was sold to a consortium of private owners".

In the context of the restructuring of New Zealand that occurred from the 1980 s there are a myriad of similar stories, hence the basic tale is very familiar: the old ways were bad, there was a little pain from the change to the new ways, but there was no alternative. Given the latest developments that see Tranz Rail significantly reducing its railway commitments, it is easy to be a little cynical about this story, but we need to take the proximal analysis a little further than simple cynicism. Following McHoul (1987), we need to avoid two types of naive position in analysing such stories. The first he calls naive relativism which is the model that people are roles $\mathrm{X}$, Y, or Z because they talk in a certain way. With our example, this would be to say that the author performs being a corporate manager because she is able to talk in the appropriate corporate fashion - to reiterate the corporation's foundation story. The second is naive realism, which is the model that people talk in certain ways because they really are roles $\mathrm{X}, \mathrm{Y}$, or $\mathrm{Z}$. This equates to the view that there is no artifice involved: the corporate manager talks in this way because she is the corporate manager, what she says comes directly from who she is, and by extension Tranz Rail really holds to the Historical Perspective story. McHoul's argument is that these views are unhelpful as they both take the mistaken approach of assuming that either how the talk is done, or whichever of the social roles and identities there are, precede, or 'cause' the other. The alternative model is to focus on how talk and identities are mutually constitutive - a key concern of proximal (micro) sociology.

If we can link 'mutual constitution' with culture then we may have a better understanding of the Inquiry and some interesting insights into the culture problem. To do this I now want to use Harvey Sacks' conception of culture, as elaborated by Miller and McHoul (1998). Consistent with a proximal view, Sacks wanted to know how a culture formed - the techniques people know, use and share that establish a common culture. If a culture exists then one can presume that its members have both, methods for producing cultural objects (like the Historical Perspective story), and methods for recognising them as those cultural objects (i.e., corporate members of Tranz Rail somehow recognise it as their story). As McHoul and Miller note, the question of how production relates to recognition has received much theoretical effort, but it could be the assumption that these are two different moments of a culture where the difficulty lies. Sacks offers a powerful insight on this issue:

A culture is an apparatus for generating
recognizable actions; if the same
procedures are used for generating as for
detecting, that is perhaps as simple a
solution to the problem of recognizability
as is formulatable (Sacks 1995 cited in
Miller and McHoul, 1998: 179).

The paradigm here is types of conversation. For example, courtroom language is generated via preallocation of turns at talk, and consequently this preallocation makes it recognisable as formal courtroom talk, as say distinguishable from ordinary conversations where turns at talk are allocated in dynamic interchanges.

It is difficult to apply this to our current material, but we can begin by noting that absolutely nothing was said in the Historical Perspective story about accidents and injuries in the railway workplace. So, why is it there? I suggest that the story generates Tranz Rail as a mix of cultures. There are corporate-management and workplace arms of culture. These are undoubtedly connected, but the thrust of the extract is one of division and hence an attempt to shift blame and responsibility. Simplifying the Historical Perspective story yet further, what it builds up is a logic where the old, traditional way of running railways is a negative thing. To be employed for a lifetime within railways is worked up to be inflexibility, intractability, in short, a bad. This logic is generated in the story by Tranz Rail corporate culture, which then has this available to posit their answer to the culture problem. Accidents and injuries are another bad - there is no problem admitting that - but what could cause such a bad? The proffered answer (from many possibilities) is, 'like generates like' - only another bad causes further bads. Hence, it is through examining the survival of old, traditional ways of doing things within the new Tranz Rail that this culture finds an answer to the culture problem.

Space is short, so a few examples will have to suffice to exemplify this discursive technique. Here are some comments (all from Tranz Rail, 2000) focused on locomotive engineers:

\section{A particular feature of the locomotive} engineers' occupation is that no locomotive 
engineer has been recruited and trained for the last 15 years.

Many of Tranz Rails' locomotive engineers have never worked for another employee ... This means that locomotive engineers have a limited range of occupational skills to directly apply to an environment outside Tranz Rail and limited exposure to competition or external references. Their major reference point is their own experience and history. (p. 12, 2.55, 2.56)

The task of shunting and train examination has been in existence since the inception of the railway. There remains a very traditional workforce in the shunting and yard environment. (p. 12, 2.61)

Contrast this with the following comments focused on 'Mechanical Engineering Employees':

The mechanical engineers are production focused. They have a broader experience of the work force outside Tranz Rail than shunters or locomotive engineers ... It is probably fair to say that Mechanical Engineering employees are less affected by the specific railway environment and have a broader outlook as a result of a higher degree of exposure to the conduct of their profession outside of the railway environment. (P. 14, 2.76, 2.78)

This theme of tradition = bad; exposure to competition = good, continues on through the types of employees:

Freight employees are generally outside the traditional railway profession and considerably less affected by traditional railway culture than core operating staff such as shunters and locomotive engineers... Many freight handling employees have worked for other employers... Tranz Rail employees involved in the maintenance and construction of infrastructure ... have a traditional culture in the same way as locomotive engineers and long-serving shunters.... most infrastructure employees have not worked for another employer and their skills are not readily transferable outside the railway industry. $(P .15,2.80,2.82,2.84,2.90)$

I suggest that someone not familiar with the types of workers who suffered the most accidents and injuries at Tranz Rail could accurately predict from the above extracts who they were. Ultimately, there is nothing hidden about Tranz Rail's line of argument here. While the value of long-serving staff is recognised,

Equally, however, the culture of long service and tradition can be obstacles to improving safety in the workplace. Traditional and entrenched mind-sets amongst operating staff about the way in which their jobs are carried out can be difficult to alter and accordingly can make new practices designed to increase safety, more difficult to implement and enforce (p. 20,3.6).

The final statement on the culture problem appears at first glance to offer a break on the tradition = bad equation:

In the future Tranz Rail proposes to continue with leadership, communication and behavioural change programmes (such as the Accident Prevention Programme and Project BEST) that focus on enhancing the traditional positive safety culture within Tranz Rail. (p. 34, 5.12)

But even here we see the pervasive logic of Tranz Rail corporate culture: the previously bad word 'tradition' can only be mentioned as something positive if it is in the same breath as 'change' words (of course, a 'good'). That is, we can venture the existence of a 'traditional positive safety culture' because it is being enhanced; it is going though a behavioural change programme. All of this is not difficult to understand and interpret, precisely because Tranz Rail is a culture: 'A culture is, in fact, where we recognise what you are doing because, for all of us, culturally, that is how we would do it' (ibid: 179). Note that this does not mean that there is agreement about ends, means, and results; rather it is precisely in the discourse of the hybrid forum that ends, means and results are made visible. They are the outcome and not the cause of the Inquiry's debates and controversies (see Latour, 1987).

\section{Conclusion}

Writing now after the Inquiry's final report has been released we can say that this argument was not given much credence - Tranz Rail was found wanting in many respects. But I would like to finish by suggesting that the things my proximal analysis has pointed to are important, and likely to be pervasive in corporate culture. What we have seen is culture-in-action, a text displaying ordering processes, the attempt to make results that are hard and fast. You want to know whether workplace culture could be involved in the deaths and injuries at Tranz Rail? Well then, first you have to know how Tranz Rail transformed an inflexible, unprofitable government monopoly into a profitable, efficient arm of a multinational corporation. In generating this cultural story the effect is also to make available the resources for generating an answer to the culture problem. It is a variant of an age-old logic: bad begets bad. It is inflexible workplace practices that must generate workplace accidents and injuries.

But in all of this discussion where is the answer to the question of whether workplace culture was a significant factor in the deaths and injuries at Tranz Rail? I have not attempted an answer, but to see this as a failure is to accept 
that this is the best question for a micro-sociologist to be answering. I hope to have provided some food for thinking in an alternative, proximal fashion. The 'hybrid forum' of the Inquiry was indeed a 'cultural battle', but one where the weapons of war were mainly textual-discursive in nature. To see how important texts and documents are here, we can use a thought-experiment: in what ways would such inquiries, and the whole field of occupational health and safety, differ if there were no texts, only oral means of translation?

Finally, there is a critical point to be made. The logic that tradition as a bad, as inflexibility, should be looked to for an answer to the culture problem is not hidden in Tranz Rail's textual response - it is easy enough for any reader to find. This leaves us with an important question: "why was Tranz Rail not able to interrogate its own cultural products?' Had it become akin to a 'total institution' where dissenting voices could not be heard, where the equation, 'profits = (with alarming regularity) bad deaths and injuries', is simply someone else's (wrong) cultural product? Certainly, the final report of the Ministerial Inquiry (2000) did not buy the Tranz Rail line, in fact, most of their consideration of the culture problem is taken up not with a possible answer, but with rejecting Tranz Rail's 'old culture is the problem' argument. The final sentence admonishes Tranz Rail to re-examine management attitudes to ensure that, at critical times, frontline managers do not place a greater priority on maintaining productivity than on safety' ('Ministerial Inquiry', 2000: $45)$.

So, Tranz Rail did not successfully win others to their view of the culture problem. Indeed, the argument presented here is that they were effectively hoist with their own petard: in attempting to answer the culture problem what came through was the relative rigidity of their own culture. As this culture was constructed in their submission it simultaneously constructed a selective (and rejected) answer to the culture problem. By now New Zealanders are well used to hearing 'There Is No Alternative' (TINA) as a justification for constant change and restructuring. As illustrated by the material above, it is no longer just a convenient rhetoric but has become embodied within the corporations themselves. Just what this means for the future regulation and improvement of workplace health and safety we simply do not know. There are always alternatives, but if TINA is so embedded in corporate culture, some important actors will simply not look for them, nor include them in the texts and documents that are so crucial to modern organisational life.

\section{Future Research}

Studies of the workplace and discourse need to overcome the either/or of the traditional agency/structure debate (Heracleous and Hendry, 2000). People in the workplace talk and they write; these are foundational social and cultural practices both for putting together work itself, and in determining what to do when things go wrong in the workplace (e.g. accidents and injuries). Macro pictures of the social distribution of accidents and injuries are useful, but we need more studies of the dynamic processes that enable statistics to exist in the first place. There is much research that could be done focusing on how textual material is produced, circulated, interpreted, and made effective within the workplace, in short, how the workplace is a 'textually mediated social organisation'.

\section{References}

Armstrong, H. (2000) Personal communication.

Callon, M. (1998) An Essay on Framing and Overflowing. Callon, M. (ed.) The Laws of the Market Oxford: Blackwell/Sociological Review: 244-269.

Cooper, R. and Law, L. (1995) Organisation: Distal and Proximal Views. Bacharach, S.B, Gagliardi, P. and Mundell, B. (eds) Research in the Sociology of Organizations Greenwich: JAI Press: 237-274.

Heracleous, L. and Hendry, J. (2000) Discourse and the study of organization. Human Relations 53(10): 1251-1286.

Latour, B. (1987) Science in Action Cambridge: Harvard University Press.

McHoul, A. (1987) Language and Institutional Reality. Organisation Studies 8 (4): 363-373.

Miller, T. and McHoul, A. (1998) Popular Culture and Everyday Life. London: Sage.

Ministerial Inquiry into Tranz Rail Occupational Safety and Health (2000) Report to the Ministers of Labour and Transport unpublished report.

O'Neill, J. (2000) Review of Meaning of a Disability by Albert Robillard. Body and Society 6(2) 101102.

Parker, M. (2000) 'The Sociology of Organizations and the Organization of Sociology' Sociological Review 48(1): 124-146.

Smith, D. (1990) Texts, Facts, and Femininity. London: Routledge.

Tranz Rail Limited (2000) Section 5 in Tranz Rail Occupational Safety and Health Inquiry: Tranz Rail submission unpublished submission.

Williams, R. (1988) Keywords (revised edition) Hammersmith: Fontana. 


\section{Author}

\section{Mike Lloyd}

Lecturer

Sociology \& Social Policy

Victoria University of Wellington

PO Box 600

Wellington

mike.lloyd@vuw.ac.nz 